\title{
Clinical and Non-Clinical Aspects of Distal Radioulnar Joint Instability
}

\author{
M.M.E. Wijffels ${ }^{*}{ }^{, 1}$, P.R.G. Brink ${ }^{2}$ and I.B. Schipper ${ }^{1}$ \\ ${ }^{1}$ Leiden University Medical Center, Department of Surgery-Traumatology, P.O. Box 9600, 2300 RC Leiden, The \\ Netherlands \\ ${ }^{2}$ Maastricht University Medical Center, Dept. of Surgery and Traumatology, P.O. Box 616, 6200 MD Maastricht, The \\ Netherlands
}

\begin{abstract}
Untreated distal radioulnar joint (DRUJ) injuries can give rise to long lasting complaints. Although common, diagnosis and treatment of DRUJ injuries remains a challenge. The articulating anatomy of the distal radius and ulna, among others, enables an extensive range of forearm pronosupination movements. Stabilization of this joint is provided by both intrinsic and extrinsic stabilizers and the joint capsule. These structures transmit the load and prevent the DRUJ from luxation during movement. Several clinical tests have been suggested to determine static or dynamic DRUJ stability, but their predictive value is unclear. Radiologic evaluation of DRUJ instability begins with conventional radiographs in anterioposterior and true lateral view. If not conclusive, CT-scan seems to be the best additional modality to evaluate the osseous structures. MRI has proven to be more sensitive and specific for TFCC tears, potentially causing DRUJ instability. DRUJ instability may remain asymptomatic. Symptomatic DRUJ injuries treatment can be conservative or operative. Operative treatment should consist of restoration of osseous and ligamenteous anatomy. If not successful, salvage procedures can be performed to regain stability.
\end{abstract}

Keywords: Distal radioulnar joint, DRU-joint, instability, wrist.

\section{INTRODUCTION}

Traumatic injuries to the distal radioulnar joint (DRUJ) may give rise to long lasting complaints of pain and restricted function in the wrist and hand. Solitary DRUJ injuries are common, although they more often accompany distal radius fractures. Diagnosis and treatment of DRUJ injuries remain challenging. A high index of suspicion, effective diagnostic procedures and knowledge of the anatomical stabilizing structures are prerequisites for adequate diagnosis and treatment. This paper provides an overview of anatomy, clinical presentation, radiologic evaluation and treatment options related to stability and instability of the DRUJ.

\section{ANATOMY}

The distal radioulnar articulation is formed by the distal sides of the radius and the ulna, the sigmoid notch and ulnar seat, respectively (Fig. 1a).

Due to the parallel positioning of the surfaces, with a difference in articulating curvature, the DRUJ provides proand supination in an extensive range, but yields stabilization [1] (Fig. 1b).

The DRUJ obtains stabilization from the joint capsule, the triangular fibrocartilage complex (TFCC) and the capsule surrounding structures. The capsule is a tripartite structure, continuous with the radioulnar ligaments of the TFCC and

*Address correspondence to this author at the Leiden University Medical Center, Department of Surgery-Traumatology, Address: P.O. Box 9600, 2300 RC Leiden, the Netherlands; Tel: +31.71.526.9111;

Fax: +31.71.526.6750; E-mail: M.M.E.Wijffels@lumc.nl

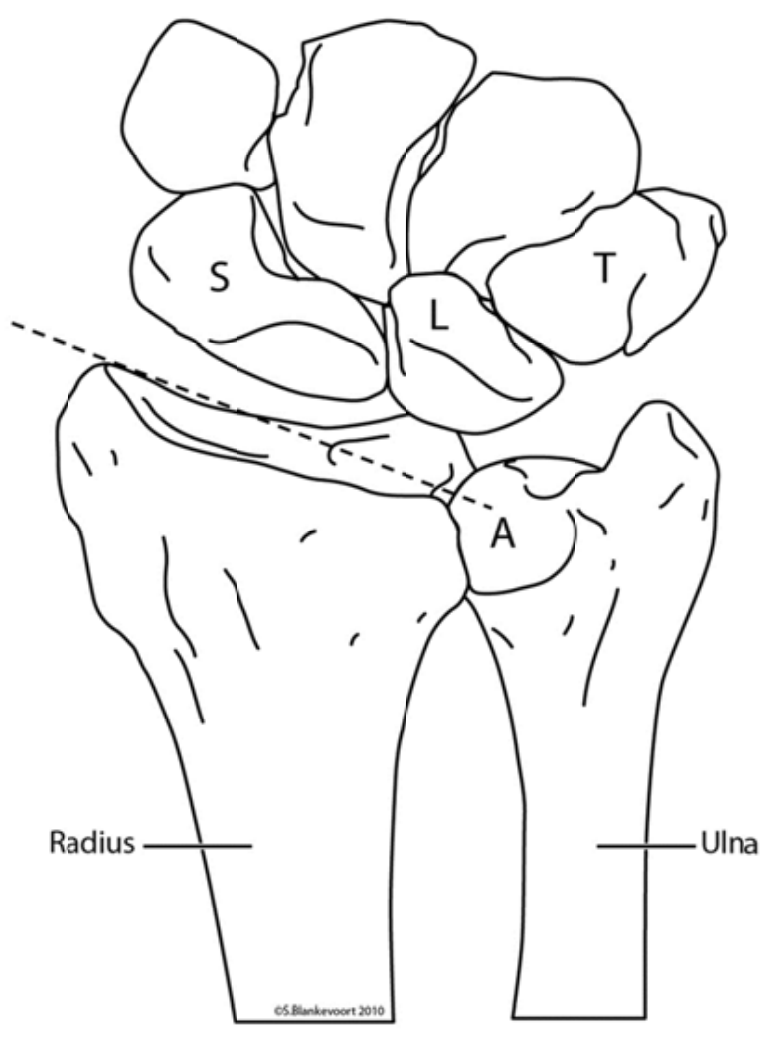

Fig. (1a). The distal radioulnar articulation is formed by the distal sides of the radius and the ulna, the sigmoid notch and ulnar seat (A) respectively. The inclination of the radius (striped line) differs from the ulnar inclination. $\mathrm{S}=$ scaphoid bone, $\mathrm{L}=$ lunate bone, $\mathrm{T}=$ triquetral bone. 
the floor of the extensor carpi ulnaris (ECU) tendon sheet. Although closely associated with surrounding structures, the capsule remains an autonomous structure. Inferiorly the capsule originates from the proximal border of the sigmoid notch and is continuous with the interosseous membrane (IM). On the volar side the capsule comprises thin areas, adapting to dorsal translation of the radius during supination. Volarly the capsule is continuous with the radioulnar ligaments of the TFCC. Reinforcing oblique fibres, among others, protect the radius from dorsal luxation. Dorsally, on the ulnar side, the capsule is in intimate contact with the ECU sheet and has reinforcing fibres at its insertion on the radial aspect of the ulna [2].

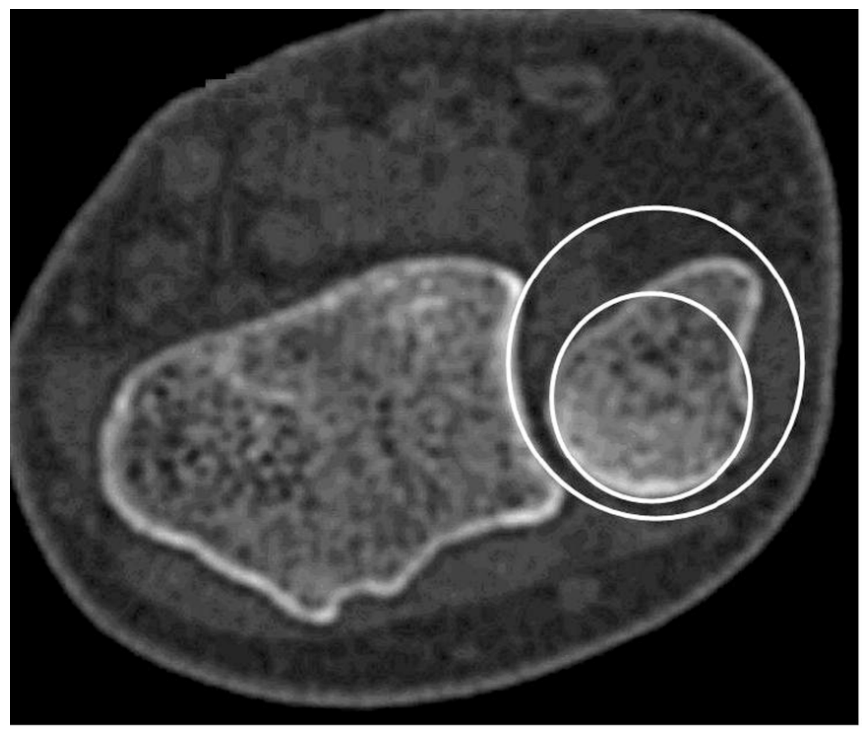

Fig (1b). The ulnar seat has a smaller radius (small circle) compared to the sigmoid notch (large circle).

\section{EXTRACAPSULAR ANATOMY}

The musculus extensor carpi ulnaris (ECU) is located on the dorso-medial side of the forearm. The ECU tendon inserts at the base of the 5th metacarpal and transverses the ulnocarpal joint through a fibro-osseous tunnel (sixth dorsal compartment), attached to the ulnar head [3] (Fig. 2).

The musculus pronator quadratus (MPQ) is situated on the volar side of the wrist, surrounded by a thin fascia. The distal insertion of the MPQ fascia is the prominent palmar crest on the radius and the articular border of the ulna where it assembles the joint capsule. On the ulnar side, the MPQ develops two heads. The superficial head inserts on the medial intermuscular septum on the ulna. The deep head of the MPQ is in direct contact with the IM [4]. The IM originates on the radius and inserts on the ulna, approximately 6 centimetres distal from the radial head. It is continuous with the DRUJ capsule and contains three reinforced regions. These regions are mainly responsible for the stability in longitudinal and transverse directions. Beside serving as a forearm stabilizer, the IM serves as the origin for flexors and extensors of the wrist [5].

\section{TFCC}

The TFCC consists of five parts; the articular disc, the superficial and deep (ligamentum Subcruentum) radioulnar fibers, and the two disc-carpal ligaments [6] (Fig. 3).

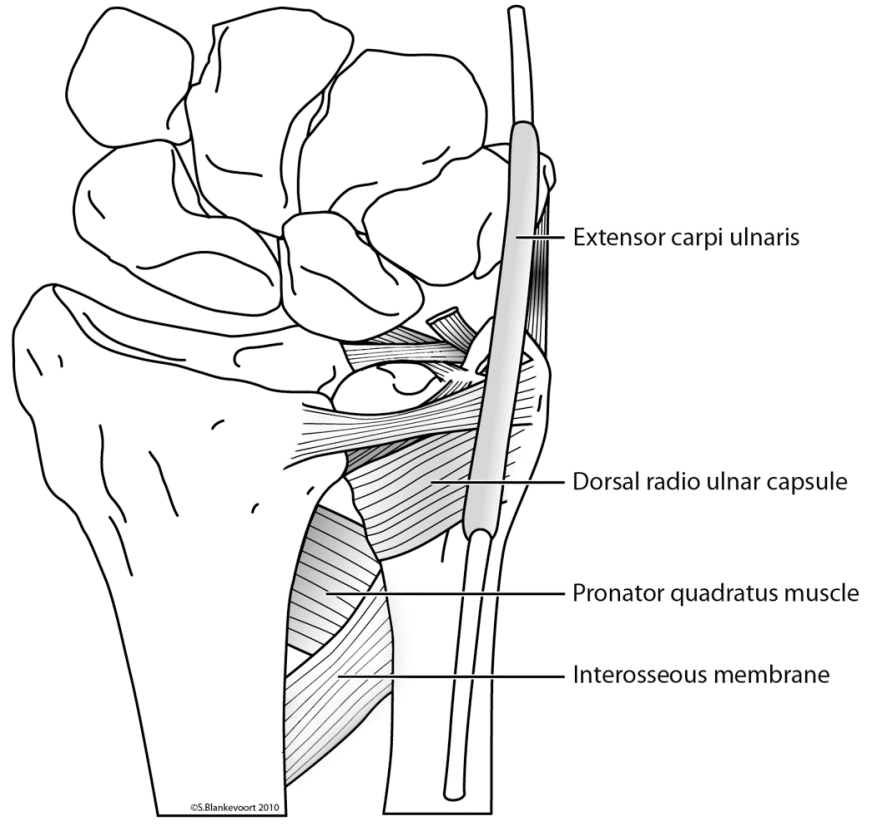

Fig. (2). The main extracapsular stabilizers of the DRU joint with one of the three reinforced areas of the interosseous membrane.

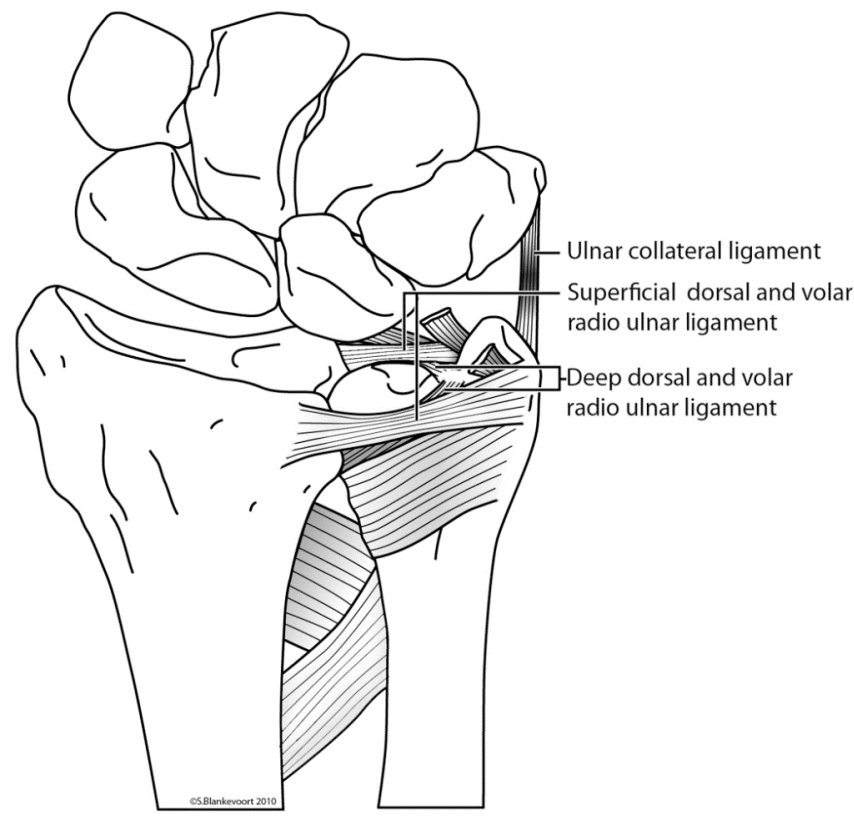

Fig. (3). The triangular fibrocartilage complex. The disc (not drawn in this figure) is stretched between ulna and radius proximally and lunate and triquetral bones distally. The two ulno-carpal ligaments are the ligaments that are partially resected in this figure.

The disc is a strong fibrocartilage structure, stretched between ulna and radius proximally and lunate and triquetral bones distally. The base of the disc is attached to the distal edge of the sigmoid notch; the incisura ulnaris radii. The apex of the disc is inserted to the depressed area of the ulnar head; the basistyloid fovea. It is continuous with the ulnar collateral ligament. On the volar side the disc is continuous with the ulnocarpal ligament, inserting on the lunate, triquetral and capitate bones $[7,8]$. The dorsal and palmar radioulnar fibers originate from the medial border of the distal radius and insert on the ulna at two distinct sites; deep 
fibers at the ulnar fovea and superficial fibers at the ulnar styloid (Fig. 4).

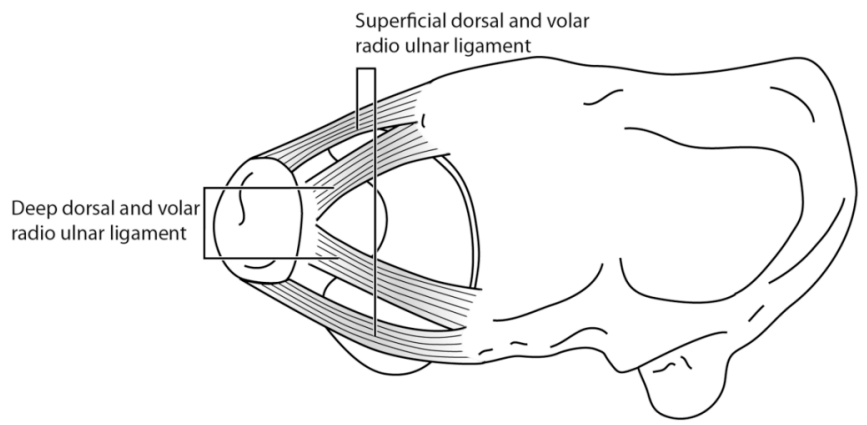

Fig. (4). The dorsal and palmar radioulnar fibers originate from the medial border of the distal radius and insert on the ulna at two distinct sites; deep fibers at the ulnar fovea and superficial fibers at the ulnar styloid.

\section{BIOMECHANICS}

\section{Pronosupination}

The four primary components of the 'forearm joint': the radiocapitellar joint, the proximal radioulnar joint, the IM and the DRUJ allow $180^{\circ}$ of pro- and supination of the forearm. With the radius rotating around the fixed ulna, in maximum pronation of $90^{\circ}$, the two forearm bones are essentially parallel and the interosseous space will be at maximum width. The rotational movement gives rise to a translational movement of the radius relative to the distal ulna. In supination the ulnar head is positioned relative palmar and in pronation relative dorsal, to the radius. These combined movements result in a complex anatomical area, called the "centrode of rotation", rather than a single center of rotation on the ulnar fovea $[9,10]$. The biomechanics of DRUJ instability therefor primarily concern the dislocation of a rotating radius around a fixed ulna. Contrary to what is often thought, it is not the ulna that is dislocating.

\section{Stability}

Stability is defined as equality of forces, with their specific moments, working on a fixed fulcrum. When load is applied on the hand, the fixed fulcrum is the DRUJ (Fig. 5).

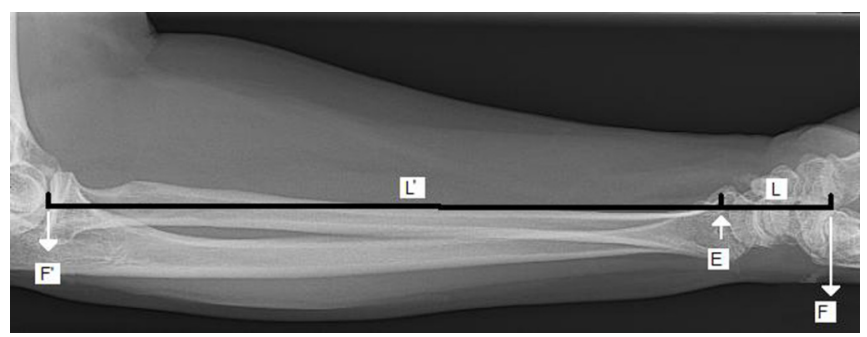

Fig (5). When load is applied to the hand (F) with a specific moment ( L), the fixed fulcrum (E) is the DRUJ. Stability is defined as equality in forces, with their specific moments, working on a fixed fulcrum. If the elbow is stable, the load between elbow and DRUJ (F' $x$ L') will equal the load between the DRUJ and the hand $(\mathrm{F} \mathrm{x} \mathrm{L)}$ ) in a stable situation.

To resist gravity, stability of the elbow and DRUJ is needed. Focusing on the DRUJ, this stability is provided extrinsic, by extracapsular structures, and intrinsic by intracapsular structures.
Extrinsic stability is provided by (1) the ECU tendon with its semi rigid sixth dorsal compartment [3,11], (2) the musculus pronator quadratus [12] and (3) the interosseous membrane [13]. Tensioning of the ECU tendon and MPQ in supination results in increased DRUJ stability $[3,9,11,14]$. The distal oblique fibers of the IM prevent the distal radius from luxation during rotation [5,13,15-19].

The primary intrinsic stabilizer of the DRUJ is the TFCC, predominantly the radioulnar ligaments of the TFCC. Additional stability is provided by the DRUJ capsule, which allows pronosupination without anterioposterior luxation. Early theories about the effect of the TFCC on DRUJ stability, suggested unique, non-collaborating roles for both deep and superficial radioulnar fibers $[1,20]$. Hagert stated that in pronation, the dorsal superficial fibers tighten, as do the deep palmar fibers. Conversely, in supination, the palmar superficial radioulnar fibers tighten, as do the deep dorsal fibers [10] (Fig. 6a, b).

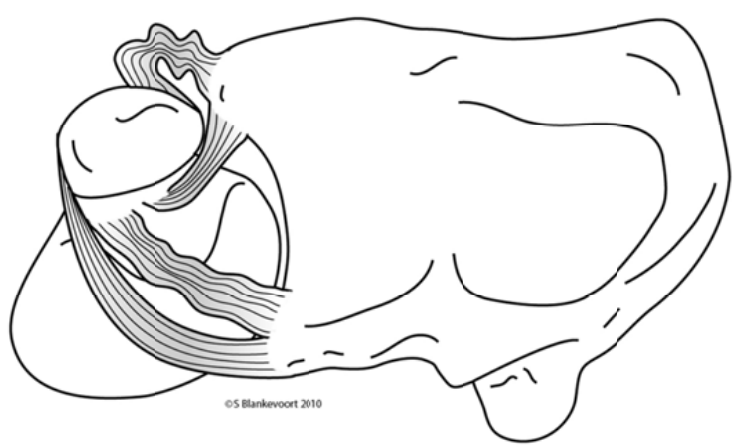

Fig. (6a). When the radius rotates around the ulna in pronation, the dorsal superficial fibers tighten, as do the deep palmar fibers.

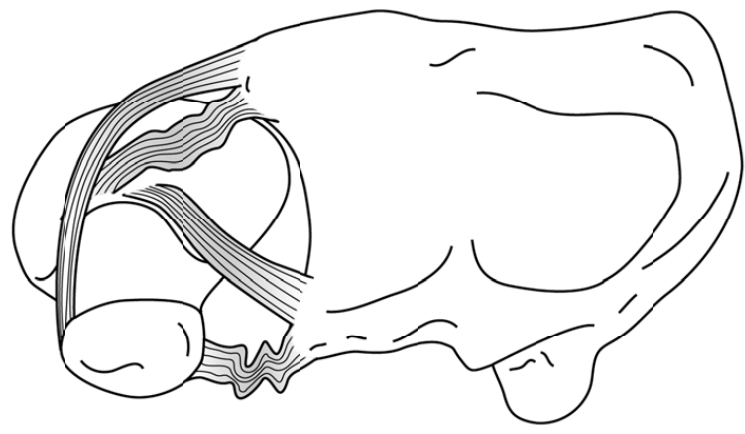

Fig (6b). When the radius rotates around the ulna in supination, the palmar superficial radioulnar fibers tighten, as do the deep dorsal fibers.

A less important mechanism of DRUJ stabilization, is the shift of the principal axis of load bearing. In maximal pronation and supination, the dorsal and volar radioulnar capsule respectively prevent the ulna from luxation [1].

\section{CLINICAL PRESENTATION OF RADIOULNAR INSTABILITY}

Although the radius is rotating around the ulna, ulnar dislocation is described, by convention, relative to the radius [21]. Suspicion of DRUJ instability should increase after a 
Table 1. Different Methods for Testing DRUJ Instability. Each Test is Explained and their Specific Characteristics are Described

\begin{tabular}{|c|c|c|c|c|c|}
\hline Name & How to Perform & Positive if: & Tested Stabilizer & Sensitivity (\%) & Specificity (\%) \\
\hline Stress test/ballottement & $\begin{array}{l}\text { Elbowflexion } 90^{\circ} \text {, fingers to the } \\
\text { ceiling. Dorsopalmar movement of } \\
\text { the ulna in respect to the radius in } \\
\text { maximal pronation and supination }\end{array}$ & $\begin{array}{l}\text { Painful or DRUJ } \\
\text { laxity }\end{array}$ & $\begin{array}{l}\text { Palmar and dorsal } \\
\text { lig. subcruentum }\end{array}$ & 66 & 68 \\
\hline Radius pull test & $\begin{array}{l}\text { Elbowflexion } 90^{\circ} \text {, wrist in neutral } \\
\text { position, pulling the radius in } \\
\text { longitudinal direction }\end{array}$ & $\begin{array}{l}\text { Ulnar variance } \\
\text { increases during } \\
\text { pulling under } \\
\text { fluoroscopy }\end{array}$ & $\begin{array}{l}\text { Interosseous } \\
\text { membrane }\end{array}$ & $\begin{array}{l}\text { Up to } 100 \% \text { in } \\
\text { cadaveric studies }\end{array}$ & $\begin{array}{l}\text { Up to } 100 \% \text { in } \\
\text { cadaveric studies }\end{array}$ \\
\hline Clunk test & $\begin{array}{l}\text { Compress ulna to the radius } \\
\text { during passive pronosupination }\end{array}$ & $\begin{array}{l}\text { A clunk is palpable } \\
\text { for the patient }\end{array}$ & $\begin{array}{l}\text { Interosseous } \\
\text { membrane }\end{array}$ & Not available & Not available \\
\hline ECU test & $\begin{array}{l}\text { Elbowflexion } 90^{\circ} \text {, hand in ulnar } \\
\text { deviation, active pronosupination }\end{array}$ & $\begin{array}{l}\text { Abnormal motion } \\
\text { ECU tendon }\end{array}$ & ECU tendon & Not available & Not available \\
\hline Press test & $\begin{array}{l}\text { Patient pushes himself up from } \\
\text { seated position with use of } \\
\text { affected wrist }\end{array}$ & $\begin{array}{l}\text { Focal ulnar sided } \\
\text { wrist pain }\end{array}$ & TFCC & $100 \%$ & Not available \\
\hline
\end{tabular}

history of wrist trauma, and restricted or painful pro- and supination. In specific cases of solitary distal ulna luxation the empty sulcus or groove for the ECU tendon can be palpated, in maximal supination on the head of the ulna. This is due to the ECU and the TFCC which are displaced into the DRUJ [22]. Acute DRUJ instability accompanying a distal radius fracture, will be difficult to diagnose due to the swelling and deformity around the wrist joint. In chronic DRUJ instability, volar translation of the ulnar head is most frequently due to radial malunion, rather than to instability [23].

\section{Testing Instability}

In testing the DRUJ, a distinction should be made between static and dynamic instability. Static instability is defined as laxity of the DRUJ with a non-rotating distal radius, as compared to the unaffected side. Dynamic instability can only be tested during forearm rotation. Only a small number of physical tests for determining DRUJ instability have been described. (Table 1).

The stress test for static DRUJ instability (Fig. 7), also known as the "piano sign" or ballottement maneuver, is mostly used but its diagnostic value remains disputed [16, 23-25].

The radius pull test, as described by Essex-Lopresti [2628], can diagnose longitudinal forearm instability.

Dynamic DRUJ instability can be diagnosed using the clunk test or the extensor carpi ulnaris test [16,29]. Presence of TFCC-lesions can be tested using the press-test [30]. The clinical value of the press-test is unclear, since not every TFCC tear is associated with DRUJ instability [31,32]. Furthermore the correlation between physical examination and radiologic outcome remains unclear [33].

\section{RADIOLOGIC EVALUATION}

\section{Conventional Radiographs}

Anterioposterior (AP) and true lateral radiographs of both wrists should be made to compare the injured with the uninjured side. Secure positioning is essential in this respect.
Projection of the pisiform bone over the distal part of the scaphoid indicates a pure lateral view $[34,35]$.

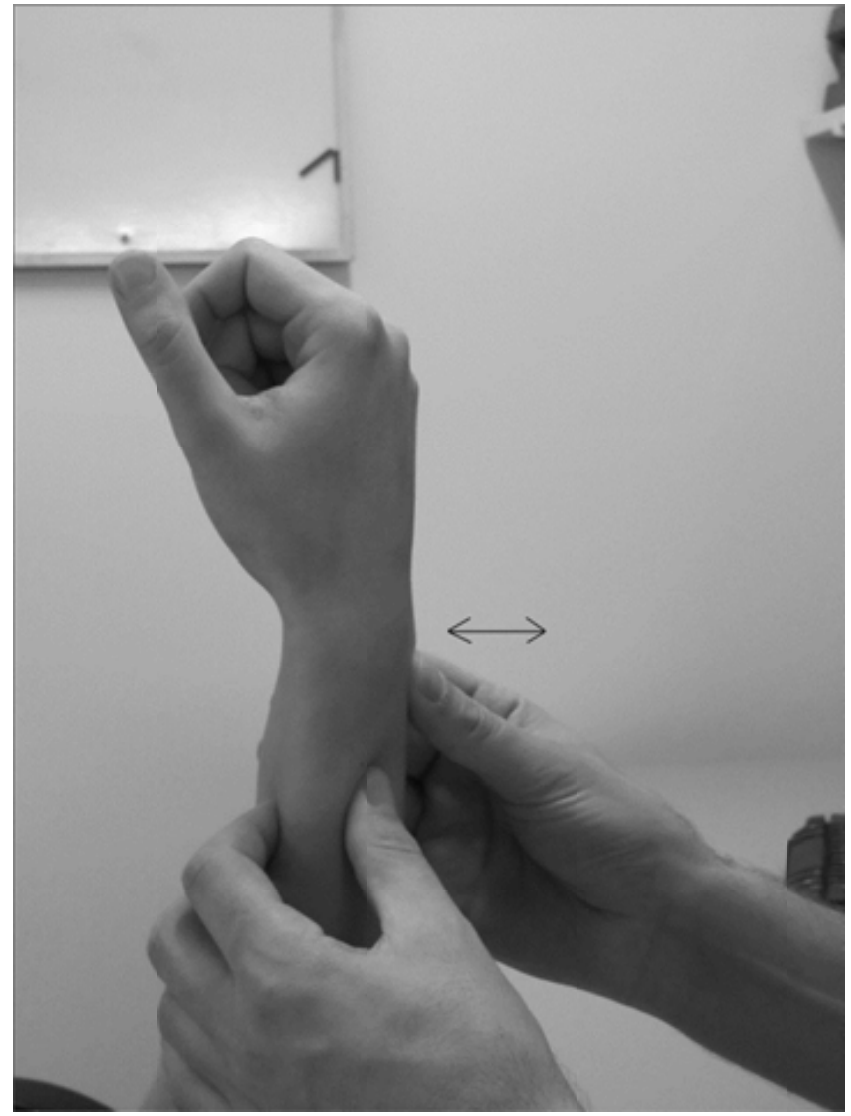

Fig. (7). The stress-test is performed by provoking anterolateral movement of the radius, while stabilizing the ulna. By comparing the stability of both the injured with the non-injured wrist, DRUJ instability can be diagnosed.

A direct radiographic sign that indicates DRUJ instability, is widening of the distal radioulnar space on the AP radiograph, relative to the unaffected side. On the true lateral view a radioulnar distance of $6 \mathrm{~mm}$ or more, between the most dorsal cortices, indicates DRUJ instability. If this 
distance measures 4 to $5 \mathrm{~mm}$ then further investigation is needed [36]. Indirect signs, that may indicate DRUJ instability, are an ulnar styloid base fracture, $15^{\circ}$ or more dorsal tilting of the distal radius, avulsion of the ulnar fovea, radial shortening of more than $4 \mathrm{~mm}$. and a radial inclination less than $0^{\circ}[37,38]$.

\section{Articulogram}

Radiopaque liquids injected intra-articularly, with repeated or continuous radiographs, facilitate visualization of the articular ligamentous borders. Articulograms of the wrist will only provide indirect signs that may account for DRUJ instability [39]. Nowadays, the articulogram is little used, due to the introduction of magnetic resonance imaging.

\section{Computed Tomography}

When conventional radiographs are inconclusive, computed tomography scan (CT scan) can be of additional value in diagnosing DRUJ instability [40]. A diagnostic protocol should include imaging of both wrists in maximal pronation, neutral position and maximal supination. Several techniques to define (sub)luxation have been suggested. The subluxation ratio method has been proven to be most useful [41-45]. CT has its advantages in detecting DRUJ instability, but malunions may account for a false positive outcome.

\section{Magnetic Resonance Imaging}

Compared to CT scan, magnetic resonance (MR) has greater sensitivity for soft tissue contrast but provides less osseous details. Several techniques have been suggested to define DRUJ instability using MR [46]. High resolution MRI provides a potential tool for diagnosing ulnar styloid fractures and TFCC tears, however the role of MR in evaluating direct signs of DRUJ instability remains unclear $[47,48]$.

\section{Arthroscopy}

Arthroscopy has become popular when diagnosing TFCC tears, that may account for DRUJ instability, and their subsequent treatment. Furthermore, arthroscopy is sensitive in the evaluation of the articulating surfaces of the distal radius and ulna as part of treatment strategy [49].

\section{CLASSIFICATION}

Only one classification can be found for DRUJ instability. Seo and colleagues suggested a classification based on the outcome of the stress test [50]. Operative treatment is predominantly reserved for symptomatic laxity or spontaneous subluxation of the DRUJ.

\section{TREATMENT}

Before considering operative treatment of DRUJ instability, patients' symptoms must be evaluated thoroughly. Painless DRUJ instability occurs in about one third of the patients after a distal radius fracture [24]. In asymptomatic DRUJ instability, a "wait and see" policy can be advocated [24,31]. If symptomatic DRUJ dislocation is diagnosed, conservative treatment will only be successful in the presence of a congruent DRUJ.

An acute dorsal dislocation can be reduced with digital pressure on the distal ulna combined with forceful supination. A full-arm cast should be maintained for 6 weeks. Conclusive evidence for the preferred wrist position is lacking [51, 52]. An acute volar dislocation should be reduced with digital pressure on the volar side in forceful pronation. Indications for operative treatment are interposition of soft tissue preventing manual reduction, a locked DRUJ or persisting DRUJ instability due to a fracture of the volar lip of the sigmoid notch [53]. Open reduction techniques are described by Gibson and Cox $[54,55]$. Lesions in the IM, as seen in Essex-Lopresti injury, need stabilization of both the radial head and the DRUJ.

Chronic DRUJ instability can be treated by functional bracing if patients are unwilling or unfit for surgery [56].

For operative treatment of chronic DRUJ instability, both anatomical and non-anatomical techniques can be used. The first step in anatomic reconstruction consists of analysis of osseous alignment. Malalignment needs to be corrected if present. However, the need for re-insertion of a fractured or non-united ulnar styloid base is still a matter of debate. The second step is reconstruction of the intrinsic and extrinsic stabilizing structures, which can be done with open or arthroscopic procedures. When it is not possible to reconstruct the stabilizers, non-anatomic stabilization, using the surrounding tendons, may be indicated [57,58]. In general, results of non-anatomic treatment options, such as tenodesis using the flexor carpi ulnaris or the ECU tendon, are disappointing [59-61]. If non-anatomic DRUJ reconstructions give rise to complaints, several salvage procedures or ulnar head replacement have been suggested [62-67].

\section{CONCLUSION}

DRUJ instability is a common but frequently missed diagnosis. It is mostly associated with distal radius fractures. A malpositioned or lax distal ulna during physical examination, must give rise to suspicion of DRUJ instability. The presence of direct or indirect signs on conventional roentgenography may indicate DRUJ instability as well. Currently, CT scans are favored for further osseous radiologic evaluation, as is MR for ligamentous evaluation. If DRUJ instability is present, only one classification can be referred to. In acute situations, non-operative treatment can be successful after anatomical reduction. In operative treatment, the first step is restoration of anatomy by correction of osseous malalignment, followed by soft tissue repair. If not successful, non-anatomical stability should be provided, otherwise salvage procedures should be carried out.

\section{ACKNOWLEDGEMENT}

Declared none.

\section{CONFLICT OF INTEREST}

Declared none.

\section{REFERENCES}

[1] Ekenstam F, Hagert CG. Anatomical studies on the geometry and stability of the distal radio ulnar joint. Scand J Plast Reconstr Surg 1985; (1): 17-25.

[2] Kleinman WB, Graham TJ. The distal radioulnar joint capsule: clinical anatomy and role in posttraumatic limitation of forearm rotation. J Hand Surg Am 1998; 23(4): 588-99. 
[3] Spinner M, Kaplan EB. Extensor carpi ulnaris. Its relationship to the stability of the distal radio-ulnar joint. Clin Orthop Relat Res 1970; 68: 124-9.

[4] Gerber A, Masquelet AC. Anatomy and intracompartmental pressure measurement technique of the pronator quadratus compartment. J Hand Surg Am 2001; 26(6): 1129-34.

[5] Poitevin LA. Anatomy and biomechanics of the interosseous membrane: its importance in the longitudinal stability of the forearm. Hand Clin 200; 17(1): 97-110.

[6] Mikic ZD. Detailed anatomy of the articular disc of the distal radioulnar joint. Clin Orthop Relat Res 1989; 245: 123-32.

[7] Bednar MS, Arnoczky SP, Weiland AJ. The microvasculature of the triangular fibrocartilage complex: its clinical significance. J Hand Surg Am 1991; 16(6): 1101-5.

[8] Thiru RG, Ferlic DC, Clayton ML, McClure DC. Arterial anatomy of the triangular fibrocartilage of the wrist and its surgical significance. J Hand Surg Am 1986; 11(2): 258-63.

[9] King GJ, McMurrey RY, Rubenstein JD, Gertzbein SD. Kinematics of the distal radioulnar joint. J Hand Surg Am 1986; 11(6): 798-804.

[10] Hagert CG. Distal radius fracture and the distal radioulnar joint anatomical considerations. Handchir Mikrochir Plast Chir 1994; 26(1): 22-6.

[11] Goldner JL, Hayes MG. Stabilization of the remaining ulna using one-half of the extensor carpi ulnaris tendon after resection of the distal ulna. Orthop Trans 1979; 3: 330-1.

[12] Ruby LK, Ferenz CC, Dell PC. The pronator quadratus interposition transfer: an adjunct to resection arthroplasty of the distal radioulnar joint. J Hand Surg Am 1996; 21(1): 60-5.

[13] Hotchkiss RN, An KN, Sowa DT, Basta S, Weiland AJ. An anatomic and mechanical study of the interosseous membrane of the forearm: pathomechanics of the proximal migration of the radius. J Hand Surg Am 1989; 14(2 Pt 1): 256-61.

[14] Palmer AK, Werner FW. The triangular fibrocartilage complex of the wrist-anatomy and function. J Hand Surg Am 1981; 6(2): 15362.

[15] Gofton WT, Gordon KD, Dunning CE, Johnson JA, King GJ. Soft tissue stabilizers of the distal radioulnar joint: an in vitro kinematic study. J Hand Surg Am 2004; 29(3): 423-31.

[16] Jupiter JB. Commentary: The effect of ulnar styloid fractures on patient-rated outcomes after volar locking plating of distal radius fractures. J Hand Surg Am 2009; 34(9): 1603-4.

[17] Noda K, Goto A, Murase T, Sugamoto K, Yoshikawa H, Moritomo $\mathrm{H}$. Interosseous membrane of the forearm: an anatomical study of ligament attachment locations. J Hand Surg Am 2009; 34(3): 41522.

[18] Pfaeffle HJ, Manson TT, Tomaino MM, Woo SL, Herndon JH. Role of the forearm interosseous ligament: is it more than just longitudinal load transfer? J Hand Surg Am 2000; 25(4): 683-8.

[19] Watanabe H, Berger RA, Berglund LJ, Zobitz ME, An KN. Contribution of the interosseous membrane to distal radioulnar joint constraint. J Hand Surg Am 2005; 30(6): 1164-71.

[20] Schuind F, An KN, Berglund L, et al. The distal radioulnar ligaments: a biomechanical study. J Hand Surg Am 1991; 16(6): 1106-14.

[21] Dameron TB Jr. Traumatic dislocation of the distal radio-ulnar joint. Clin Orthop Relat Res 1972; 83: 55-63.

[22] Paley D, McMurry RY, Murray JF. Dorsal dislocation of the ulnar styloid and extensor carpi ulnaris tendon in the distal radioulnar joint: The empty sulcus sign. J Hand Surg Am 1987; 12(6): 102932 .

[23] Kim JP, Park MJ. assessment of distal radioulnar joint instability after distal radius fracture: comparison of computed tomography and clinical examination results. J Hand Surg Am 2008; 33(9): 1486-94.

[24] Lindau T, Hagbert L, Aldercreutz C, Johnsson K, Aspenberg P. Distal radioulnar instability is an independent worsening factor in distal radial fractures. Clin Orthop Relat Res 2000; 376: 229-35.

[25] Szabo RM. Distal radioulnar joint instability. J Bone Joint Surg Am 2006; 88(4): 884-94.

[26] Davidson PA, Moseley JB Jr., Trullos HS. Radial head fracture. A potentially complex injury. Clin Orthop Relat Res 1993; 297: 22430.

[27] Essex-Lopresti P. Fractures of the radial head with distal radioulnar dislocation; report of two cases. J Bone Joint Surg Br 1951; 33B(2): 244-7.
[28] Smith AM, Urbanosky LR, Castle JA, Rushing JT, Ruch DS Radius Pull Test: Predictor of longitudinal forearm instability. J Bone Joint Surg Am 2002; 84-A(11): 1970-6.

[29] Burkhartt SS, Wood MB, Lindscheid RL. Posttraumatic recurrent subluxation of the extensor carpi ulnaris tendon. J Hand Surg Am1982; 7(1): 1-3.

[30] Lester B, Halbrecht J, Levy IM, Gaudinez RL. "Press test" for office diagnosis of triangular fibrocartilage complex tears of the wrist. Ann Plast Surg 1995; 35(1): 41-5.

[31] Lindau T, Adlercreutz C, Aspenberg P. Peripheral tears of the triangular fibrocartilage complex cause distal radioulnar joint instability after distal radial fractures. J Hand Surg Am 2000; 25(3): 464-8.

[32] Palmer AK. Triangular fibrocartilage disorders: injury patterns and treatment. Arthroscopy 1990; 6(2): 125-32.

[33] Pirela-Cruz MA, Goll SR, Klug M, Windler D. Stress computed tomography analysis of the distal radioulnar joint: a diagnostic tool for determining translational motion. J Hand Surg Am 1991; 16(1): 75-82.

[34] Epner RA, Bowers WH, Guilford WB. Ulna variance-the effect of wrist positioning and roentgen filming technique. J Hand Surg Am 1982; 7(3): 298-305.

[35] Mino De, Palmer AK, Levinsohn EM. The role of radiography and computed tomography in the diagnosis of subluxation and dislocation of the distal radioulnar joint. J Hand Surg Am 1983; 8(1): 23-31.

[36] Nakamura R, Horii E, Imaeda T, Tsunoda K, Nakao E.. Distal radioulnar joint subluxation and dislocation diagnosed by standard roentgenography. Skeletal Radiol 1995; 24(2): 91-4.

[37] Pogue DJ, Viegas FS, Patterson RM, et al. Effects of distal radius fracture malunion on wrist joint mechanics. J Hand Surg Am1990; 15(5): 721-7.

[38] Watanabe H, Berger RA, Berglund LJ, et al. Contribution of the interosseous membrane to distal radioulnar joint constraint. J Hand Surg Am 2005; 30(6): 1164-71.

[39] Levinsohn EM, Rosen ID, Palmer AK. Wrist arthrography: value of the three-compartment injection method. Radiology 1991; 179(1): 231-9.

[40] Mino DE, Palmer AK, Levinsohn EM. Radiography and computerized tomography in the diagnosis of incongruity of the distal radio-ulnar joint. A prospective study. J Bone Joint Surg Am 1985; 67(2): 247-52.

[41] Lo IK, MacDermid JC, Bennett JD, Bogoch E, King GJ. The radioulnar ratio: a new method of quantifying distal radioulnar joint subluxation. J Hand Surg Am 2001; 26(2): 236-43.

[42] Mino DE, Palmer AK, Levinsohn EM. The role of radiography and computed tomography in the diagnosis of subluxation and dislocation of the distal radioulnar joint. J Hand Surg Am 1983; 8(1): 23-31.

[43] Nakamura R, Horii E, Imaeda T, Nakao E. Criteria for diagnosing distal radioulnar joint subluxation by computed tomography. Skeletal Radiol 1996; 25(7): 649-53.

[44] Park MJ, Kim JP. Reliability and normal values of various computed tomography methods for quantifying distal radioulnar joint translation. J Bone Joint Surg Am 2008; 90(1): 145-53.

[45] Wechsler RJ, Wehbe MA, Rifkin MD, Edeiken J, Branch HM. Computed tomography diagnosis of distal radioulnar subluxation. Skeletal Radiol 1987; 16(1): 1-5.

[46] Staron RB, Feldman F, Haramati N, Singson RD, Rosenwasser M, Esser PD. Abnormal geometry of the distal radioulnar joint: MR findings. Skeletal Radiol 1994; 23(5): 369-72.

[47] Anderson ML, Skinner JA, Felmlee JP, Berger RA, Amrami KK. Diagnostic comparison of 1.5 Tesla and 3.0 Tesla preoperative MRI of the wrist in patients with ulnar-sided wrist pain. J Hand Surg Am 2008; 33(7): 1153-9.

[48] Magee T. Comparison of 3-T MRI and arthroscopy of intrinsic wrist ligament and TFCC tears. AJR Am J Roentgenol 2009; 192(1): 80-5.

[49] Atzei A. New trends in arthroscopic management of type 1-B TFCC injuries with DRUJ instability. J Hand Surg Eur Vol 2009; 34(5): 582-91.

[50] Seo KN, Park MJ, Kang HJ. Anatomic reconstruction of the distal radioulnar ligament for posttraumatic distal radioulnar joint instability. Clin Orthop Surg 2009; 1(3): 138-45. 
[51] Garcia-Elias M, Dobyns JH. Dorsal and palmar dislocations of the distal radioulnar joint. In: Cooney WP, Ed. The wrist: diagnosis and operative treatment. St. Louis: Mosby 2010.

[52] Linscheid RL Disorders of the distal radioulnar joint. In: Cooney WP, Ed. The wrist: diagnosis and operative treatment. St. Louis: Mosby 1998.

[53] Paley D, Rubenstein J, McMurrey RY. Irreducible dislocation of distal radial ulnar joint. Orthop Rev 1986; 15(4): 228-31.

[54] Cox FJ. Anterior dislocation of the distal extremity of the ulna: report of a case. Surgery 1942;12: 11-3.

[55] Gibson A. Uncomplicated dislocation of the inferior radio-ulnar joint. J Bone Joint Surg 1925; 7: 180-9.

[56] Millard GM, Budoff JE, Paravic V, Noble PC. Functional bracing for distal radioulnar joint instability. J Hand Surg Am 2002; 27(6): 972-7.

[57] Lawler E, Adams BD. Reconstruction for DRUJ instability. Hand (NY) 2007; 2(3): 123-6.

[58] Scheker LR, Belleiappa PP, Acosta R, German DS. Reconstruction of the dorsal ligament of the triangular fibrocartilage complex. J Hand Surg Br 1994; 19 (3): 310-8.

[59] Breen TF, Jupiter JB. Extensor carpi ulnaris and flexor carpi ulnaris tenodesis of the unstable distal ulna. J Hand Surg Am 1989; 14(4): 612-7.
[60] Hui FC, Linscheid RL. Ulnotriquetral augmentation tenodesis: a reconstructive procedure for dorsal subluxation of the distal radioulnar joint. J Hand Surg Am 1982; 7(3): 230-6.

[61] Tsai TM, Stilwell JH. Repair of chronic subluxation of the distal radioulnar joint (ulnar dorsal) using flexor carpi ulnaris tendon. $\mathrm{J}$ Hand Surg Br 1984; 9(3): 289-94.

[62] Bowers WH. Distal radioulnar joint arthroplasty: the hemiresection-interposition technique. J Hand Surg Am 1985; 10 (2): 169-78.

[63] Darrach W. Anterior dislocation of the head of the ulna. Ann Surg 1912; 56: 802-3.

[64] Feldon P, Terrono AL, Belsky MR. The "wafer" procedure. Partial distal ulnar resection. Clin Orthop Relat Res 1992; (275): 124-9.

[65] Herbert T, van Schoonhoven J. Ulnar head replacement. Tech Hand Up Extrem Surg 2007; 11(1): 98-108.

[66] Kapandji I. The Kapandji-Sauve operation. Its techniques and indications in non rheumatoid diseases. Ann Chir Main 1986; 5(3): 181-93.

[67] Watson H, Gabuzda G. Matched distal ulna resection for posttraumatic disorders of the distal radioulnar joint. J Hand Surg Am 1992; 17(4): 724-30.

(C) Wijffels et al.; Licensee Bentham Open.

This is an open access article licensed under the terms of the Creative Commons Attribution Non-Commercial License (http://creativecommons.org/licenses/by-nc/3.0/) which permits unrestricted, non-commercial use, distribution and reproduction in any medium, provided the work is properly cited. 